\title{
Caregiver burden among relatives of patients with schizophrenia in Katsina, Nigeria
}

\begin{abstract}
Abdulkareem Jika Yusuf, MB BS, FWACP, FMCPsych
Department of Psychiatry, Ahmadu Bello University Teaching Hospital, Zaria, Kaduna state, Nigeria
\end{abstract}

Folorunsho Tajudeen Nuhu, MB BS, FMCPsych

Federal Neuro-Psychiatric Hospital, Barnawa, Kaduna state, Nigeria

Akinsola Akinbiyi, MB BS, FMCPsych

Mercy Mental Health, Hoppers Crossing, Australia

Background. Caring for patients with schizophrenia places an enormous burden on the caregivers. The magnitude of this problem remains largely unknown in sub-Saharan Africa.

Objective. The objective of this study was to determine the nature of the burden reported by caregiving relatives of patients with schizophrenia.

Materials and method. A total of 129 primary caregivers of patients with schizophrenia attending the outpatient clinic of Katsina State Psychiatric Hospital were interviewed, using a socio-demographic data collection sheet and the Zarith Burden Interview (ZBI).

Results. The mean age of the respondents was 45.1 \pm 8.9 years. Most of the caregivers were female. A high level of burden was found in $47.3 \%$ of respondents. The level of burden experienced was significantly associated with place of residence and family size.

Conclusion. Schizophrenia is associated with a high level of caregiver burden. Efforts should be made to alleviate this burden for better outcomes in both patients and caregivers.

Schizophrenia is one of the most devastating of psychiatric disorders, leading to long-term and progressive disability in numerous individuals. These disabilities are an onerous burden on both patients and their caregivers. ${ }^{1,2}$ Caregiver burden in mental illness can either be objective or subjective. Objective burdens are defined as readily verifiable behavioural phenomena, e.g. negative patient symptoms; caregivers' lives disrupted in terms of domestic routine, social activities and leisure; social isolation; and financial and employment difficulties. ${ }^{3,4}$ Subjective burdens comprise emotional strain on caregivers, e.g. fear, sadness, anger, guilt, loss, stigma and rejection. ${ }^{4,5}$ The shift towards community care for patients with mental disease has resulted in transferring responsibility for day-to-day care of patients to their family members, ${ }^{6}$ which has lead to profound psychosocial, physical and financial burdens on patients' families.

The World Health Organization has estimated that about 40 $90 \%$ of patients with schizophrenia live with their families. ${ }^{7}$ In developing countries, the extended family provides care for these patients in the face of poor mental health facilities. ${ }^{8}$ However, recent changes in family structures and rapid economic decline in such countries are threatening the support available to patients with chronic mental illness. ${ }^{9}$ Consequently, there is a need to study the burden of caregiving in these countries.

\section{Objectives}

The objectives of the study were to determine: (i) the level of burden on caregivers who are relatives of patients with schizophrenia; and (ii) the socio-demographic correlates of the burden on caregivers among relatives of patients with schizophrenia.

\section{Study design and population}

Ours was a cross-sectional descriptive study conducted at Katsina State Psychiatric Hospital, which is a government health facility that provides both inpatient and outpatient mental health services to the entire population of Katsina state. The hospital also receives referrals from neighbouring states and the Republic of Niger. Katsina state is one of the 36 states of the Federal Republic of Nigeria, in the country's north-west and about $600 \mathrm{~km}$ from the national federal capital of Abuja. The main economic activities in the state are agriculture and small-scale trading.

The study participants were caregivers of patients with schizophrenia attending the hospital's outpatient clinic. The hospital has a policy of encouraging caregivers to attend follow-ups with patients. Caregivers of patients who had been on treatment for at least a year were enrolled for the study. The diagnosis of schizophrenia was based on fulfilling the diagnostic 
criteria for schizophrenia in the International Classification of Disease (ICD-10) on first contact with the hospital; this was ascertained from hospital records. A total of 129 caregivers who presented consecutively and fulfilled the inclusion criteria over a 3-month period from September 2008 to December 2008 were enrolled for the study. Informed consent was obtained from respondents before conducting interviews.

Ethical approval for the study was granted by the state's Health Services Management Board.

\section{Measurements}

Respondents were interviewed using the following instruments:

- Data collection sheet. This was designed to collect socio-demographic details of respondents and patients. The information included gender, age, education, income and duration of illness.

- Zarith Burden Interview (ZBI). This was developed to assess caregiver burden in relatives of patients with chronic mental illnesses. ${ }^{10}$ It is a 22 -item instrument that includes the factors most frequently mentioned by caregivers as problem areas in providing care for mentally ill patients. The factors include the caregiver's health, psychological wellbeing, finances, social life, stigma details, and relationship between patient and caregiver. The instrument has a possible score of 0 - 88, depending on the caregiver's responses. Responses are rated from $0-4$, based on the level of distress. The ZBI scores were converted into categorical responses in this study. Scores ranging from 0 to 1 were regarded as negative, while scores ranging from 2 to 4 were regarded as positive. The instrument has been used to assess caregiver burden not only in dementia but also in schizophrenia." The instrument has been validated in Nigeria among caregivers of patients with dementia. ${ }^{12}$

All the instruments were back-translated into the Hausa language and harmonised. In view of the low level of literacy among respondents, the instruments were administered by one of the authors.

\section{Data analysis}

Data were analysed using the Statistical Package for Social Sciences, Windows Version 13. The level of probability was set at $5 \%$ level of significance.

\section{Results}

\section{Socio-demographic characteristics}

A total of 129 respondents were interviewed; their mean age was $45.1 \pm 8.9$ years. The mean ages of the male and female respondents were $45.8 \pm 7.9$ and $44.7 \pm 9.4$ years, respectively. The mean age of the male and female patients was $30.3 \pm 10.4$ years and $26.2 \pm 5.9$ years, respectively. There was a significant difference in the mean ages of the male and female patients $(t=2.79, p=0.006)$. The mean duration of illness was $4.1 \pm 4.5$ years (median 2.0 years). All the patients lived with their caregivers in a multi-generational family setting. All the patients were receiving only typical antipsychotics for treatment of their illness. Other socio-demographic characteristics are shown in Table I.

\section{ZBI and socio-demographic characteristics of subjects}

The mean ZBI score was 26.4 7.9 , while the median score was 27. There was no significant difference in the ZBI scores based on the subjects' socio-demographic characteristics, as shown in Table II.

\begin{tabular}{|c|c|c|c|}
\hline & Variable & $\begin{array}{l}\text { Frequency } \\
\text { (N) }\end{array}$ & $\%$ \\
\hline 1. & $\begin{array}{l}\text { Gender } \\
\text { Male } \\
\text { Female }\end{array}$ & $\begin{array}{l}42 \\
87\end{array}$ & $\begin{array}{l}32.6 \\
67.4\end{array}$ \\
\hline 2. & $\begin{array}{l}\text { Education } \\
\text { Formal education } \\
\text { No education }\end{array}$ & $\begin{array}{l}65 \\
64\end{array}$ & $\begin{array}{l}50.4 \\
49.6\end{array}$ \\
\hline 3. & $\begin{array}{l}\text { Place of residence } \\
\text { Rural } \\
\text { Urban }\end{array}$ & $\begin{array}{l}56 \\
73\end{array}$ & $\begin{array}{l}43.4 \\
56.6\end{array}$ \\
\hline 4. & $\begin{array}{l}\text { Relationship with } \\
\text { patient } \\
\text { Parent } \\
\text { Sibling }\end{array}$ & $\begin{array}{l}63 \\
66\end{array}$ & $\begin{array}{l}48.8 \\
51.2\end{array}$ \\
\hline 5. & $\begin{array}{l}\text { Gender of patient } \\
\text { Male } \\
\text { Female }\end{array}$ & $\begin{array}{l}60 \\
69\end{array}$ & $\begin{array}{l}46.5 \\
53.5\end{array}$ \\
\hline 6. & $\begin{array}{l}\text { Employment status of } \\
\text { patient } \\
\text { Employed } \\
\text { Unemployed }\end{array}$ & $\begin{array}{l}67 \\
62\end{array}$ & $\begin{array}{l}51.9 \\
48.0\end{array}$ \\
\hline 7. & $\begin{array}{l}\text { Financial support } \\
\text { Yes } \\
\text { No }\end{array}$ & $\begin{array}{l}65 \\
64\end{array}$ & $\begin{array}{l}50.4 \\
49.6\end{array}$ \\
\hline
\end{tabular}




\begin{tabular}{|c|c|c|c|c|}
\hline & Variable & Mean & $t$-value & p-value \\
\hline \multirow[t]{3}{*}{1.} & Gender & & & \\
\hline & Male & $26.9 \pm 7.5$ & 0.50 & 0.58 \\
\hline & Female & $26.1 \pm 8.1$ & & \\
\hline \multirow[t]{3}{*}{2.} & Place of residence & & & \\
\hline & Rural & $26.1 \pm 7.7$ & 0.38 & 0.70 \\
\hline & Urban & $26.6 \pm 8.0$ & & \\
\hline \multirow[t]{3}{*}{3.} & Patient gender & & & \\
\hline & Male & $27.6 \pm 6.9$ & 1.66 & 0.09 \\
\hline & Female & $25.9 \pm 8.5$ & & \\
\hline \multirow[t]{3}{*}{4.} & Employment & & & \\
\hline & Employed & $27.7 \pm 6.7$ & 1.37 & 0.17 \\
\hline & Unemployed & $25.4 \pm 8.9$ & & \\
\hline \multirow[t]{3}{*}{5.} & Family size & & & \\
\hline & $<5$ & $26.2 \pm 5.0$ & 0.98 & 0.89 \\
\hline & $\geq 5$ & $26.4 \pm 8.2$ & & \\
\hline \multirow[t]{3}{*}{6.} & Education & & & \\
\hline & Formal education & $27.1 \pm 5.4$ & 1.11 & 0.27 \\
\hline & No education & $25.6 \pm 9.7$ & & \\
\hline
\end{tabular}

\section{Level of caregiver burden}

A high level of caregiver burden was found in 61 (47.3\%) respondents. A higher level of caregiver burden was significantly associated with place of residence and family size. The relationships between levels of caregiver burden and sociodemographic characteristics of respondents are as shown in Table III.

\section{Respondents' answers to ZBI}

Analysis of responses to items on the ZBI showed that factors related to stigma, negative behaviours of the patients and financial constraints were the caregivers' three most-reported causes of burden. Overall, 97 (75.2\%) respondents indicated experiencing an enormous burden as a result of caring for their relatives (Table $\mathrm{N}$ ).

\section{Discussion}

The preponderance of female respondents in this study is consistent with the tradition of the area. In most sub-Saharan African communities, females are the traditional caregivers for patients with chronic illnesses. The pattern of living arrangements is multi-generational in nature, which is an advantage to the patient in terms of the large number of potential caregivers. This factor is more important in the absence of sheltered accommodation facilities for patients with chronic mental illness in Nigeria. Similar observations were made by another study in southern
Nigeria. ${ }^{2}$ The respondents' and patients' mean ages showed that they were within the productive age group, which implies a loss of productivity that in turn has many economic implications, not only for caregivers and patients but also for the nation as a whole. The majority of patients were employed (mostly in farming) despite their illness. However, the employment status of patients is not significantly associated with the level of burden, which may be due to the enormous burden associated with the illness, and the absence of an effective health insurance scheme to pay for patients' medical expenses. As a result, the entire burden of medical bills is borne by patients and their relatives.

The mean $\mathrm{ZBI}$ scores showed no significant differences based on the respondents' or patients' socio-demographic characteristics, which could be due to the widespread burden being experienced by caregivers, irrespective of their sociodemographic characteristics. A similar observation was made by a study carried out in southern Nigeria. ${ }^{2}$

A large proportion of respondents were experiencing a high level of burden; this was significantly associated with family size and place of residence. These respondents were found to be from larger families, in contrast to those reporting a low level of burden; this might have been due to the enormous burden of caring for the family and at the same time caring for the patient with schizophrenia. Respondents from rural areas were more likely to experience a high level of burden, compared with those from urban areas, which could be because of the additional burden 
Table III. Level of burden by socio-demographic characteristics

\begin{tabular}{|c|c|c|c|c|}
\hline & Variable & High burden & Low burden & Statistics \\
\hline \multirow[t]{2}{*}{1.} & Age & & & \\
\hline & Mean age (years) & $44.2 \pm 10.7$ & $45.9 \pm 6.8$ & $t=1.54, p=29$ \\
\hline \multirow[t]{3}{*}{2.} & Education & & & \\
\hline & Formal education & 32 & 33 & $\chi^{2}=0.19, p=0.39$ \\
\hline & No education & 29 & 35 & \\
\hline \multirow[t]{3}{*}{3.} & Place of residence & & & \\
\hline & Rural & 21 & 35 & $\chi^{2}=3.80, p=0.04$ \\
\hline & Urban & 40 & 33 & \\
\hline \multirow[t]{2}{*}{4.} & Caregiver income & & & \\
\hline & Mean income (Naira) & $15164 \pm 15792$ & $24610 \pm 50998$ & $t=1.36, p=0.17$ \\
\hline \multirow[t]{3}{*}{5.} & Caregiver gender & & & \\
\hline & Male & 22 & 20 & $\chi^{2}=0.22, p=0.34$ \\
\hline & Female & 37 & 48 & \\
\hline \multirow[t]{3}{*}{6.} & Patient employment status & & & \\
\hline & Employed & 33 & 34 & $\chi^{2}=0.22, p=0.39$ \\
\hline & Unemployed & 28 & 34 & \\
\hline \multirow[t]{2}{*}{7.} & Family size & & & \\
\hline & Mean & $9.2 \pm 0.6$ & $7.4 \pm 2.5$ & $t=2.85, p=0.005$ \\
\hline \multirow[t]{2}{*}{8.} & Duration of illness & & & \\
\hline & Mean (years) & $4.0 \pm 4.4$ & $4.2 \pm 4.5$ & $t=0.28, p=0.78$ \\
\hline \multirow[t]{3}{*}{9.} & Patient gender & & & \\
\hline & Male & 29 & 31 & $\chi^{2}=0.05, p=0.86$ \\
\hline & Female & 32 & 37 & \\
\hline \multirow[t]{2}{*}{10.} & Patient age & & & \\
\hline & Mean (years) & $27.0 \pm 6.4$ & $29.0 \pm 10.0$ & $t=1.38, p=0.17$ \\
\hline \multirow[t]{3}{*}{11.} & Financial support & & & \\
\hline & Yes & 27 & 38 & $\chi^{2}=1.74, p=0.13$ \\
\hline & No & 34 & 30 & \\
\hline
\end{tabular}

Table IV. Participant responses to ZBI items

\begin{tabular}{|c|c|c|c|}
\hline & Item & Yes & No \\
\hline 1. & Ask for more help & $42(32.6)$ & $87(67.4)$ \\
\hline 2. & Not enough time for self & $64(49.6)$ & $65(50.4)$ \\
\hline 3. & Stress from caring for relative & $73(56.6)$ & $56(43.4)$ \\
\hline 4. & Embarrassed by relative's behaviour & $98(76.0)$ & $31(24.0)$ \\
\hline 5. & Feel angry when around relative & 37 (28.7) & 92 (71.3) \\
\hline 6. & Relative affects relationship with others & $21(16.3)$ & $108(83.7)$ \\
\hline 7. & Afraid of what future holds for relative & $89(69.0)$ & 40 (31.0) \\
\hline 8. & Feel relative is dependent on you & $95(73.6)$ & $34(26.4)$ \\
\hline 9. & Feel strained when around relative & $36(27.9)$ & $93(72.1)$ \\
\hline 10. & Health suffered because of relative & $63(48.8)$ & $66(51.1)$ \\
\hline 11. & Lack of privacy because of relative & $53(41.1)$ & $76(58.9)$ \\
\hline 12. & Social life suffered because of relative & 49 (38.0) & $80(62.0)$ \\
\hline 13. & Uncomfortable having friends over because of relative & $105(81.4)$ & $24(18.6)$ \\
\hline 14. & Relative seems to depend on you only & $41(31.8)$ & $88(68.2)$ \\
\hline 15. & Not enough money to care for relative & $96(74.4)$ & $33(25.6)$ \\
\hline 16. & Feel unable to care for relative much longer & $27(20.9)$ & $102(79.0)$ \\
\hline 17. & Lost control of life since relative became ill & $38(29.5)$ & $91(70.5)$ \\
\hline 18. & Wish to leave relative's care to someone else & $48(37.2)$ & $81(62.8)$ \\
\hline 19. & Uncertain about what to do with relative & $23(17.8)$ & $106(82.2)$ \\
\hline 20. & Feeling of doing more for relative & $69(53.5)$ & $60(46.5)$ \\
\hline 21. & Feel you could do better job of caring for relative & $48(37.2)$ & $81(62.8)$ \\
\hline 22. & Overall burden felt in caring for relative & 97 (75.2) & $32(24.8)$ \\
\hline
\end{tabular}


associated with travelling long distances to access medical help for their relatives.

Analysis of the various ZBI items showed that those related to financial constraints, stigma and patients' negative behaviours were the most stressful to caregivers. These factors are likely to affect the outcome of the illness and could also negatively affect the health of caregivers. Relatives with high financial burdens may be responsible for purchasing medication or paying medical bills. Stigma and negative patient behaviours may cause a relative to avoid interacting with patients.

\section{Limitation}

The study is cross-sectional, with a relatively small sample size.

\section{Conclusion}

Relatives of patients with schizophrenia face enormous burdens, with financial, stigma and negative patient behaviour being more prominent. Efforts should therefore be made by the government to provide adequate financial and psychosocial support to caregivers of patients with schizophrenia.

\section{Recommendations}

Based on the findings of this study, we recommend that efforts should be made to reduce the burden associated with caring for patients with schizophrenia. The government should subsidise the cost of treatment and make mental health facilities more accessible to the community. Emphasis should be laid on prevention, early diagnosis and prompt treatment of mental illness. Communities should be educated about the nature of mental illness in an attempt to reduce stigma. Clinicians should also pay attention to the needs of caregivers of patients with mental illness, especially schizophrenia.

\section{References}

1. Kung W. The illness, stigma, culture or immigration? Burden on Chinese-American caregivers of patients with schizophrenia. Fam Soc 2003; 84(4): 547-557.

2. Martyn-Yellowe IS. The burden of schizophrenia on the family: a study from Nigeria. BrJ Psychiatry 1992; 161(6): 779-782.

3. Kuipers L. Family burden in schizophrenia: implication for services. Soc Psychiatry Psychiatr Epidemiol 1993; 28(5): 207-210.

4. Greenberg JS, Greenly JR, McKean D, Brown R, Griffin-Francell C. Mothers caring for an adult child with schizophrenia: the effect of burden on maternal health. Family Relations 1993; 42(2): 205-211.

5. Tsang HWH, Tam PKC, Chen F, Chang M. Source of burden on families of individuals with mental illness. Int J Rehab Res 2002; 25(1): 25-32

6. Stern S, Dolan M, Staples E, Szmukler GL, Eisler I. Disruptive and Reconstructive: Narrative insight into the experience of family member caring for a relative with diagnosis of serious mental illness. Family Process 1999; 38(30): 353-369.

7. World Health Organization. Nations for Mental Illness: Schizophrenia and Public Health. Geneva: World Health Organization. www.who.int/media/en/55pdf laccessed 20 December 2008).

8. World Health Organization. Mental Health Atlas. Geneva: World Health Organization. www.globalatlast.who. int/globalatlast/default.asp /accessed 20 December 2008).

9. Patel V, Cohen A, Thara R, Gureje O. Is the outcome of schizophrenia really better in developing countries? Rev Bras Psiquiart 2006; 28(2): 149-152

10. Zarith SH, Reever KE, Bach-Peterson J. Relatives of impaired elderly: correlates of feelings of burden. Gerontologist 1980; 20(6): 649-655.

11. Hanzawa S, Tanaka G, Inadomi H, Urata M, OhtaY. Burden and coping strategies in mothers of patients with schizophrenia in Japan. Psychiatry Clin Neurosci 2008; 62(3): 256-263

12. Akinbiyi A. The psychosocial burden of caring for some Nigerians with dementia. Dissertation for Fellowship of the National Postgraduate Medical College of Nigeria (Faculty of Psychiatry), Lagos, Nigeria, 2001. 